\title{
Orthopedic management of myelomeningocele with a multidisciplinary approach: a systematic review of the literature
}

Parnian Shobeiri ${ }^{1,2,3}$, Ana Presedo ${ }^{4 \dagger}$, Amirali Karimi $^{1+}$, Sara Momtazmanesh ${ }^{1,2}$, Fardis Vosoughi ${ }^{5,6}$ and Mohammad Hossein Nabian ${ }^{5,6^{*}}$

\begin{abstract}
Background: Myelomeningocele (MMC) is the most common and severe form of spina bifida and imposes a significant burden on patients and the healthcare system. Recently, the multidisciplinary management of MMC has become popular. Herein, we aimed to review the orthopedic management, outcomes, and complications of the of patients with MMC eyeing a multidisciplinary approach.

Methods: We searched PubMed and EMBASE to find relevant studies published before August 2020. All studies that included clinical management of MMC patients and published earlier than 2000 were considered for review on the condition that they reported at least one orthopedic intervention and the rate of complications. We excluded review articles, case reports, case series, letters, commentaries, editorials, and conference abstracts. The primary and secondary goals of our review were to report the outcomes and complication rates of multidisciplinary management for MMC patients.

Results: Twenty-six studies included data for the management of 229,791 patients with MMC and were selected. Sixteen studies reported multidisciplinary management in addition to orthopedic management. From those, 11 (42.31\%) included urologic management, 13 (50\%) neurosurgical management, 11 (42.31\%) neurologic management, and 5 (19.23\%) gastrointestinal management. All studies included postnatal operations and related management. No randomized clinical trial was found in our search.

Conclusion: Orthopedic approaches play a key role in MMC management by alleviating spinal deformities, particularly scoliosis, and hip, foot, and ankle complications. However, the most appropriate management, whether surgical or non-surgical, may vary for different patients, given disease severity and the age of patients.
\end{abstract}

Keywords: Interdisciplinary, Communication, Meningomyelocele, Orthopedics, Spinal dysraphism

\footnotetext{
* Correspondence: Dr.nabian@gmail.com

${ }^{\dagger}$ Ana Presedo and Amirali Karimi contributed equally to this work.

${ }^{5}$ Department of Orthopedic and trauma surgery, Shariati Hospital and School

of Medicine, Tehran University of Medical Sciences (TUMS), Tehran, Iran

${ }^{6}$ Center of Orthopedic Trans-Disciplinary Applied Research (COTAR), Tehran

University of Medical Sciences (TUMS), Tehran, Iran

Full list of author information is available at the end of the article
}

C C The Author(s). 2021 Open Access This article is licensed under a Creative Commons Attribution 4.0 International License, which permits use, sharing, adaptation, distribution and reproduction in any medium or format, as long as you give appropriate credit to the original author(s) and the source, provide a link to the Creative Commons licence, and indicate if changes were made. The images or other third party material in this article are included in the article's Creative Commons licence, unless indicated otherwise in a credit line to the material. If material is not included in the article's Creative Commons licence and your intended use is not permitted by statutory regulation or exceeds the permitted use, you will need to obtain permission directly from the copyright holder. To view a copy of this licence, visit http://creativecommons.org/licenses/by/4.0/. The Creative Commons Public Domain Dedication waiver (http://creativecommons.org/publicdomain/zero/1.0/) applies to the data made available in this article, unless otherwise stated in a credit line to the data. 


\section{Background}

Spina bifida (SB) represents a congenital cause of disability characterized by an opening in the vertebral column [1]. In 2004, this condition held the sixth place among various congenital birth defects resulting in hospital admission in the USA [2]. According to the registry of European Surveillance of Congenital Anomalies (EUROCAT) in 2003-2007, the prevalence of SB was 0.51 per 1000 pregnancies, which makes it the most prevalent neural tube defect (NTD) [3]. Myelomeningocele (MMC), also known as open SB or SB aperta, is the most common and severe form of SB, inflicting a tremendous burden on patients and the healthcare system [4]. The responsible mechanism for this condition is the failure of neural tube closure during embryonic development, which results in a protruded spinal cord and meninges. This process leaves the underlying neural tissue vulnerable to damage $[1,5]$. MMC can be associated with other congenital disorders such as hydrocephalus and Chiari II malformation [5-8].

Orthopedic consequences may arise from MMC involving various parts of the body, including feet, spine, and hip $[9,10]$. Several orthopedic methods are used to manage these disabilities with variable success [11-14], and we will give a brief introduction regarding them in this "Background" section. Controversies regarding these methods are not addressed adequately and requires research and attention.

Foot consequences affect $80-95 \%$ of the patients and can present by clubfoot, valgus, equinus, calcaneus/calcaneovalgus, talus, etc. $[15,16]$. The Ponseti method of clubfoot, soft-tissue release, different types of osteotomy, and hemiepiphysiodesis for valgus are among the methods used to correct these abnormalities [16]. Skin complications, such as wound infection and pressure sores, osteomyelitis, delayed-union or non-union of the bones, loss of correction, avascular necrosis, and recurrence are among the complications that vary largely based on the condition and utilized technique [16-19].

Spinal surgery mostly involves correcting kyphosis, scoliosis, or lordosis. These consequences affect patients' appearance, ambulation, and quality of life by imposing consequences such as back pain and less social and personal acceptance $[20,21]$. Some of the surgical and nonsurgical management include spinal fusion, spinal orthoses, and sitting supports [13, 22]. These treatments may cause several complications, including decreased ambulation, pressure sores and other infections, implant problems, neurologic consequences, and interference with other care such as self-catheterization [23-25].

Muscle paralysis and imbalance may result in hip deformities, such as dislocation, subluxation, or contracture [26]. Surgical reduction may benefit a small population of the patients based on their level of MMC, while preserving muscle strength and maintaining the pelvic level and motion may assist many others [27, 28]. Surgical adverse effects include pathologic fractures and loss of ambulation [28, 29].

Various other sequels may occur involving other organs depending on the level of $\mathrm{MMC}$, including motor and sensory deficits, urological problems, and bowel incontinence [30-34]. Such complications may cause ambulation difficulties, diminished quality of life, and restriction of the patients' ability to attend school [3437]. Managing these potentially unfavorable consequences require a multidisciplinary approach and highly specialized care.

In this systematic review, we summarize and compare the foremost treatment approaches proposed by researchers and specialists in the field of orthopedics, eyeing a multidisciplinary approach towards other fields.

\section{Material and methods Search strategy}

This systematic review was conducted based on the guidelines of the Preferred Reporting Items for Systematic Reviews and Meta-Analyses (PRISMA) [38]. This review was registered (\#CRD42021225916) in the International Prospective Register of Systematic Reviews (PROSPERO) and the review protocol can be accessed [39].

We included all studies that evaluated MMC patients' clinical management if they reported: (1) at least one type of orthopedic intervention, (2) the rates of complications, and (3) published earlier than 2000. We excluded review articles, case reports, case series, letters, commentaries, editorials, and conference abstracts.

\section{Literature search and information sources}

Before conducting this review, we searched PROSPERO and found no systematic review with a similar topic. To identify relevant publications, we searched PubMed and EMBASE databases in August 2020. Our search protocol was designed based on MeSH (MEDLINE) keywords and Emtree (EMBASE). The main search terms included MMC, spinal dysraphism, spina bifida, multidisciplinary management, and orthopedic management. The search was performed without time, country, or language limitations. The comprehensive search strategy is illustrated (Fig. 1).

\section{Study selection and data collection}

All resulting records were imported to EndNote (version X20, Thomson Reuters, Toronto, Ontario, Canada), and duplicates were removed. Two review authors (P.S. and A.K.) independently screened all titles and abstracts. Then, full texts of all potentially relevant publications were assessed for eligibility. To find additional records, 


\section{PubMed Search Strategy:}

(Meningomyeloceles) OR

(Myelomeningocele)) OR

(Myelomeningoceles)) OR (Acquired

Meningomyelocele)) OR (Acquired

Meningomyeloceles)) OR

(Meningomyelocele, Acquired)) OR

(Meningomyeloceles, Acquired)) OR

(Myelomeningocele, Acquired)) $O R$

(Acquired Myelomeningocele)) OR

(Acquired Myelomeningoceles)) OR

(Myelomeningoceles, Acquired)) OR

(Myelocele)) OR (Myeloceles)) OR (spinal

dysraphism)

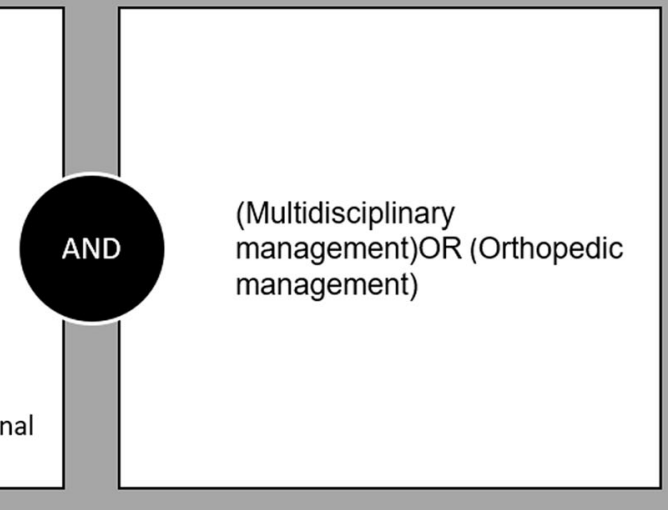

\section{EMBASE Search Strategy:}

meningomyeloceles $\mathrm{OR}$

meningomyelocele $O R$

myelomeningoceles OR (acquired AND meningomyelocele) OR (acquired AND meningomyeloceles) $O R$

(meningomyelocele, AND acquired) $O R$ (meningomyeloceles, AND acquired) OR (myelomeningocele, AND acquired) OR (acquired AND myelomeningocele) OR (acquired AND myelomeningoceles) OR (myelomeningoceles, AND acquired) OR myelocele OR myeloceles OR (spinal AND dysraphism)

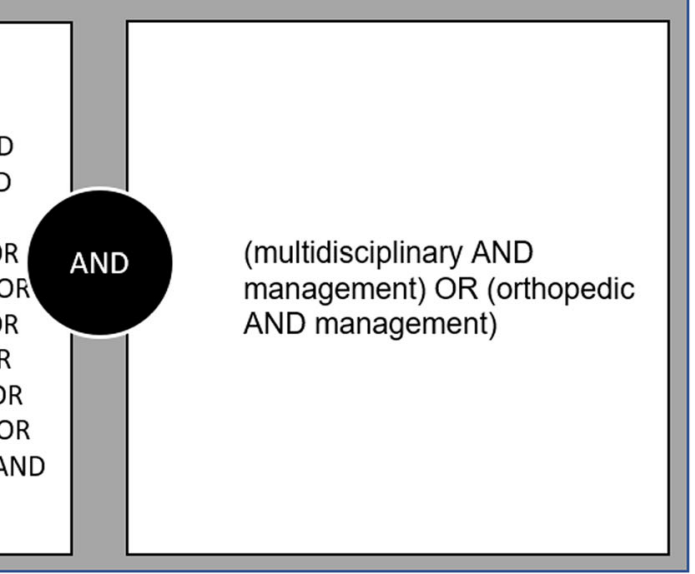

Fig. 1 Search strategy we reviewed the reference lists of the included papers. Any discrepancies between the two reviewers were solved out via discussion and consensus. If the disagreement persisted, a third reviewer (S.M.) was consulted. The PRISMA study selection diagram is illustrated to show the study selection process (Fig. 2). Two authors (P.S. and A.K.) independently extracted data from the included studies. We designed a data extraction form which included the following items: (1) general information (name of the first author, publication year, location of study, and study title), (2) patients' characteristics (number of patients and controls, mean age, sex ratio, and location of MMC), (3) management methods, (4) rates of complications, and (5) outcome of interventions.

\section{Outcome measures}

In this review, the primary outcome was the result of orthopedic management for MMC patients. Besides, we summarized other accompanied managements (e.g., urologic, neurosurgical and neurological, gastrointestinal) to reach the purpose of conducting a multidisciplinary review. Additionally, we investigated the complications of these interventions.

\section{Quality assessment}

The quality of the included studies was assessed using the Newcastle-Ottawa Scale (NOS) [40]. Based on this scale, each study can receive a score of 0-9 based on the quality of the sample selection (max 4 scores), comparability of cases and controls (max 2 scores), and assessment of the exposure/outcome (max 3 scores). In this quality assessment tool, a lower score indicates a greater risk of bias.

\section{Results}

\section{Study selection}

The search yielded 613 results (Fig. 2). After removing 150 duplicated records, our screening method led to the 


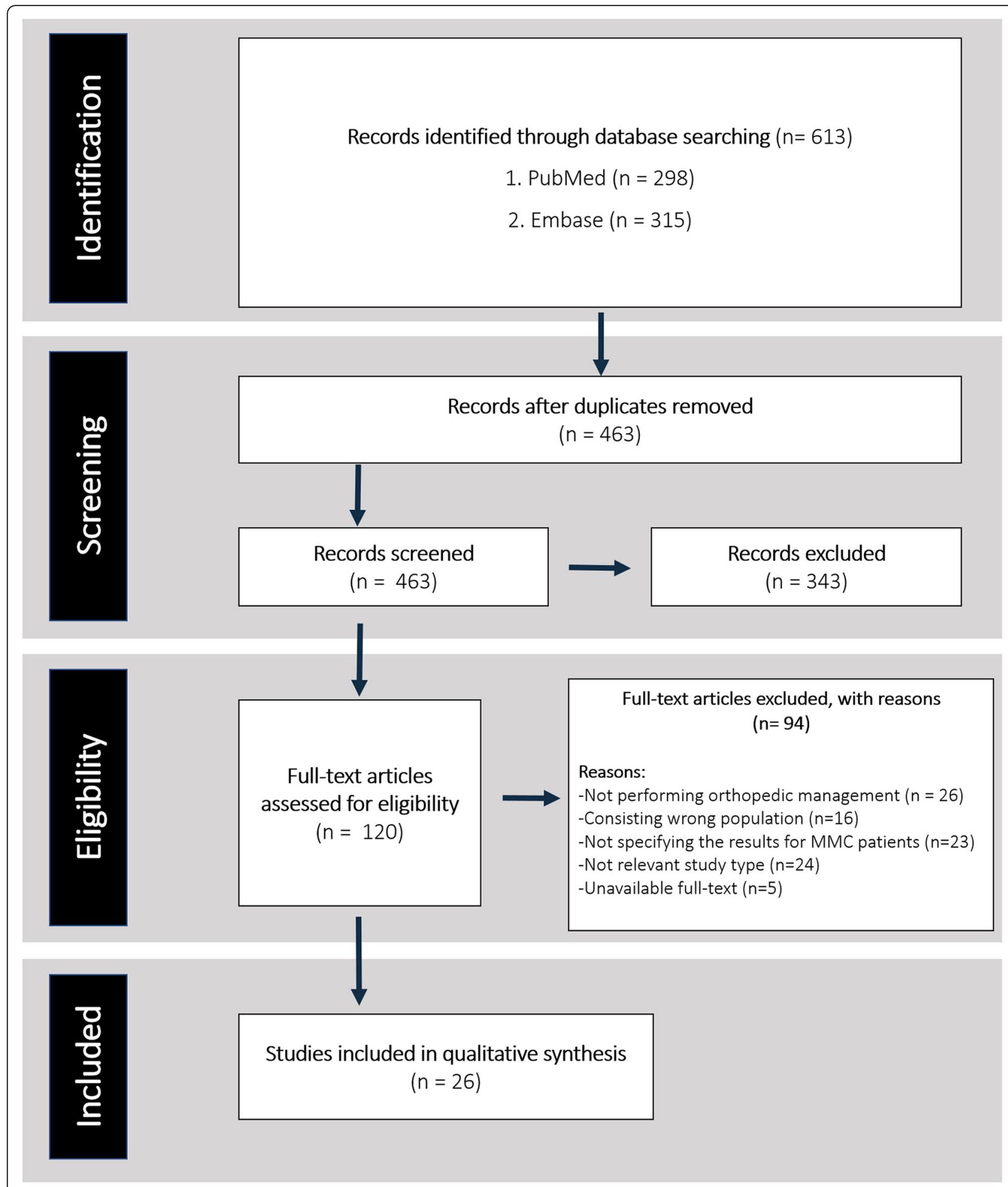

Fig. 2 Study selection process according to the Preferred Reporting Items for Systematic Reviews and Meta-Analyses (PRISMA) guideline

exclusion of 343 articles. We assessed 120 full texts for eligibility. Finally, a total of 26 studies were included [9$14,20,21,26,41-57]$.

\section{Study characteristics}

$\checkmark$ From the 26 articles included, 19 were retrospective cohorts [9-14, 20, 21, 41-45, 49, 51, 54-57], 4 were 
prospective cohorts $[26,46,52,53], 2$ were retrospective cross-sectional studies [47, 48], and 1 was a case-control study [50]. We systematically reviewed clinical management of 229,791 patients with MMC whose treatment involved at least one kind of orthopedic intervention. Sixteen studies provided other types of managements, besides orthopedic approaches, which were as follows: 11 (42.31\%) urologic management [9-11, 44, 45, 50, 51, 53, 55-57], 13 (50\%) neurosurgical management [9-11, 20, 43-45, 49, 50, 53, 55-57], 11 (42.31\%) neurologic management [9-11, 21, 44, 45, 49,53, 55-57], and 5 (19.23\%) gastrointestinal management [9, 11, 55-57]. Moreover, all the studies included described postnatal operations and management. Table 1 presents the characteristics of the selected studies.

\section{Quality assessment}

We found no randomized clinical trial (RCT) regarding this topic. Therefore, the risk of bias was assessed with the NOS for non-randomized studies (Table 2). We assessed the quality of 26 studies with a total of 234 items for the risk of bias.

All studies received 3 or 4 points in the selection domain, except one study performed by Sponseller et al. [41]. The comparability was not adequately addressed in the majority of articles. Except for three studies [13, 42, 53], the exposure/outcome assessment was fully reported. Only two studies by Gerlach et al. and Wang et al. received a full score $[46,50]$. The lowest score was 5 , which was attributed to Parsch et al. and Januschek et al. $[13,53]$.

\section{Orthopedic management}

Patients often need diverse management approaches based on the affected part of the body, including the spine, foot, and hip [58].

\section{Foot}

From the 26 studies included, five studies included interventions to correct foot deformities [12, 42, 46, 52, 54]. Four studies deal with clubfoot management [12, 46, 52, $54]$, two studies addressed the correction to valgus deformity [12, 42], and one study treated equinus deformity [12].

Clubfoot Frischhut et al. [12] studied 91 patients with SB (182 feet). Clubfoot deformity was predominantly diagnosed in children with lumbar lesions (73 out of 182 feet). From the 37 feet corrected with surgery (via Cincinnati incision) before the age of 2 years, the recurrence of clubfoot deformity was observed in 29 feet by the age of 2 , and 18 patients required a revision surgery by the age of 10 . From the 73 cases associated with a lumbar lesion, bracing was used in 70 cases before the age of 2 and in 52 cases before the age of 10. At the last followup visit, at 24.5 years, only 2 cases needed revision surgery [12].

Gerlach et al., El-Fadl et al., and Matar et al. [46, 52, 54] used the Ponseti method to treat clubfoot deformity in a total of 74 patients. Matar et al. [54] defined the outcomes after treatment of clubfoot deformity: (1) achieving plantigrade pain-free feet, and (2) the need for surgical intervention. They followed 18 feet with an average Pirani score of 5.5 (range 3.5-6.0) and performed Ponseti casts and tendo-achilles tenotomy surgery in $17(94.4 \%)$ feet. Fifteen feet (83.3\%) were functional and pain-free at the final follow-up [54], 5 of which showed recurrence. Two other studies by Gerlach et al. and El-Fadl et al. [46, 52] used the Diméglio scoring system to assess the clubfeet. Based on four minor and four major criteria, this scoring system differentiates four groups of clubfoot: (I) benign $(0-5$; > 90\% reducible), (II) moderate (5-10; > reducible but partly resistant), (III) severe (10-15; resistant but partly reducible), and (IV) very severe (15-20; almost irreducible) [59]. In the study of Gerlach et al., the mean overall Diméglio grade after treatment was 3.3 (range 3.0-3.6) in the MMC group. Out of 28 feet, 24 (86\%) required percutaneous achilles tenotomy after the initial treatment, and $19(68 \%)$ feet showed recurrence [46]. El-Fadl et al. reported that the mean Diméglio score improved significantly from 15.25 before the management to 7.42 at the last follow-up visit after the management $(P<0.001)$ [52].

Valgus A valgus foot tends to be observed in mid and lower lumbar MMC, and hindfoot surgery is usually performed to correct this deformity [60]. Frischhut et al. reported 40 feet with calcaneo-valgus deformity (14 with L3-L4 lesions and 26 with L5-sacral lesions) at 10-year follow-up despite adequate treatment. Interestingly, this value increased to 48 (16 with L3-L4 lesions and 32 with L5-sacral lesions) at the last follow-up (24.5 years old on average) [12]. In the study of Torosian et al., postoperative outcomes showed that interventions had corrected the hindfoot alignment to approximately $5^{\circ}$ of valgus. Also, the hindfoot alignment of feet varied from $0^{\circ}$ to $10^{\circ}[42]$.

Equinus and calcaneus As reported by Frischhut et al., the equinus deformity was present in 37 feet at the age of 2 years (33 with T12-L2, 2 with L3-L4, and 2 with L5-sacral lesions) [12]. At 10-year follow-up, 41 feet showed equinus deformity (21 with T12-L2, 2 with L3L4, and 18 with L5-sacral lesions), which was mainly related to an increased occurrence in patients with sacral lesions. The prevalence of calcaneus deformity decreased from 31 cases at 2 years of age (4 with T12-L2, 3 with 


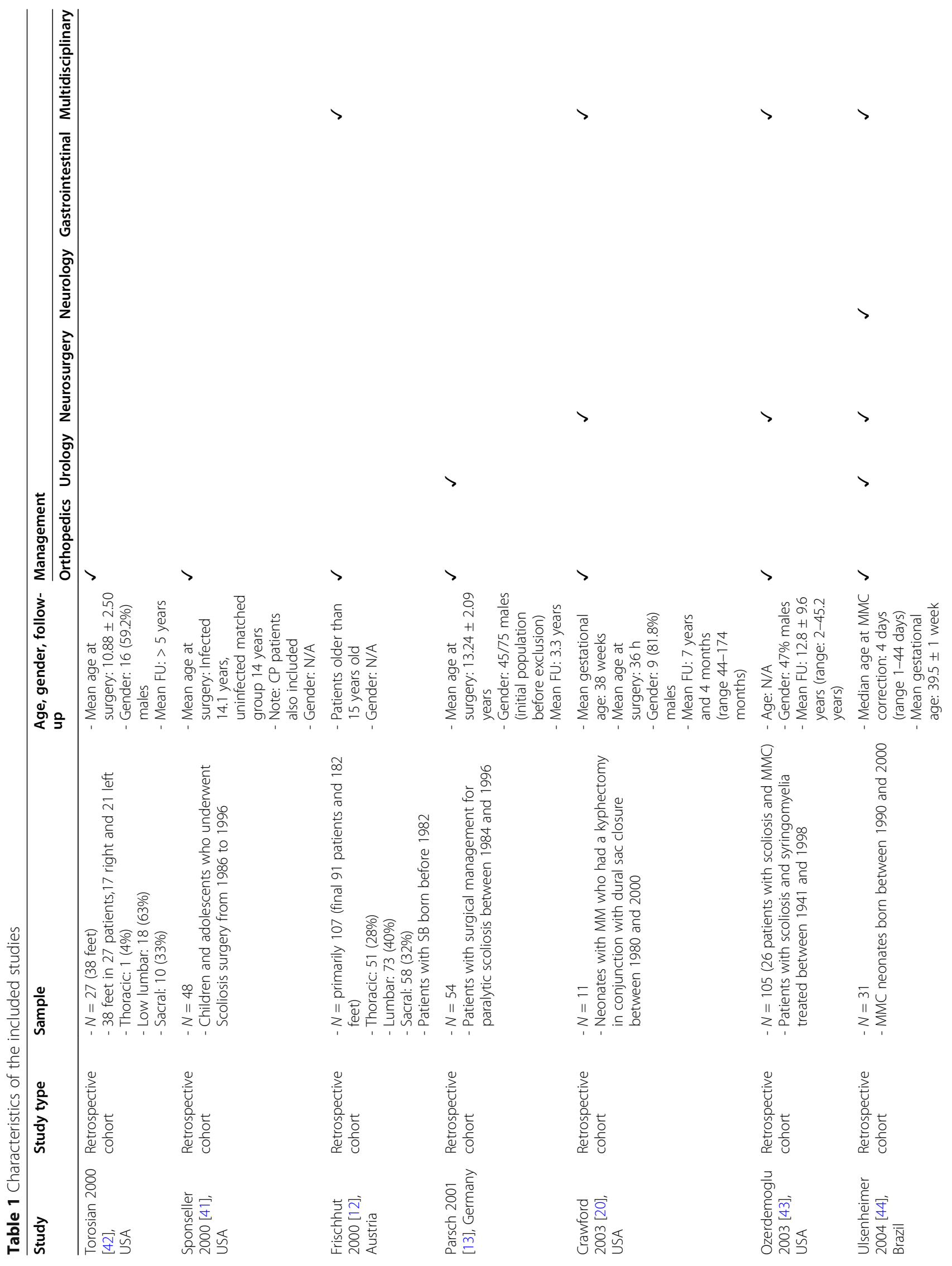




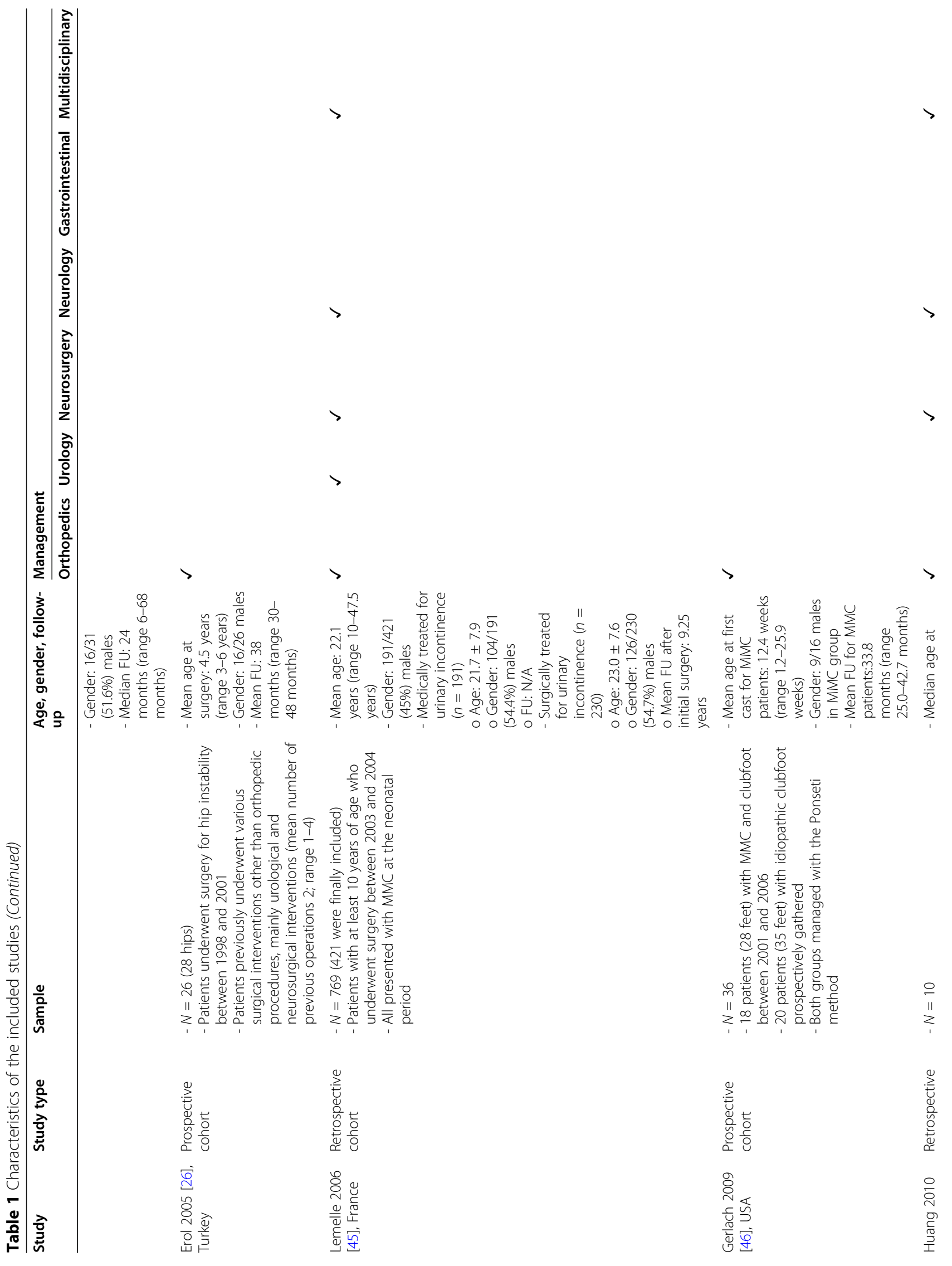




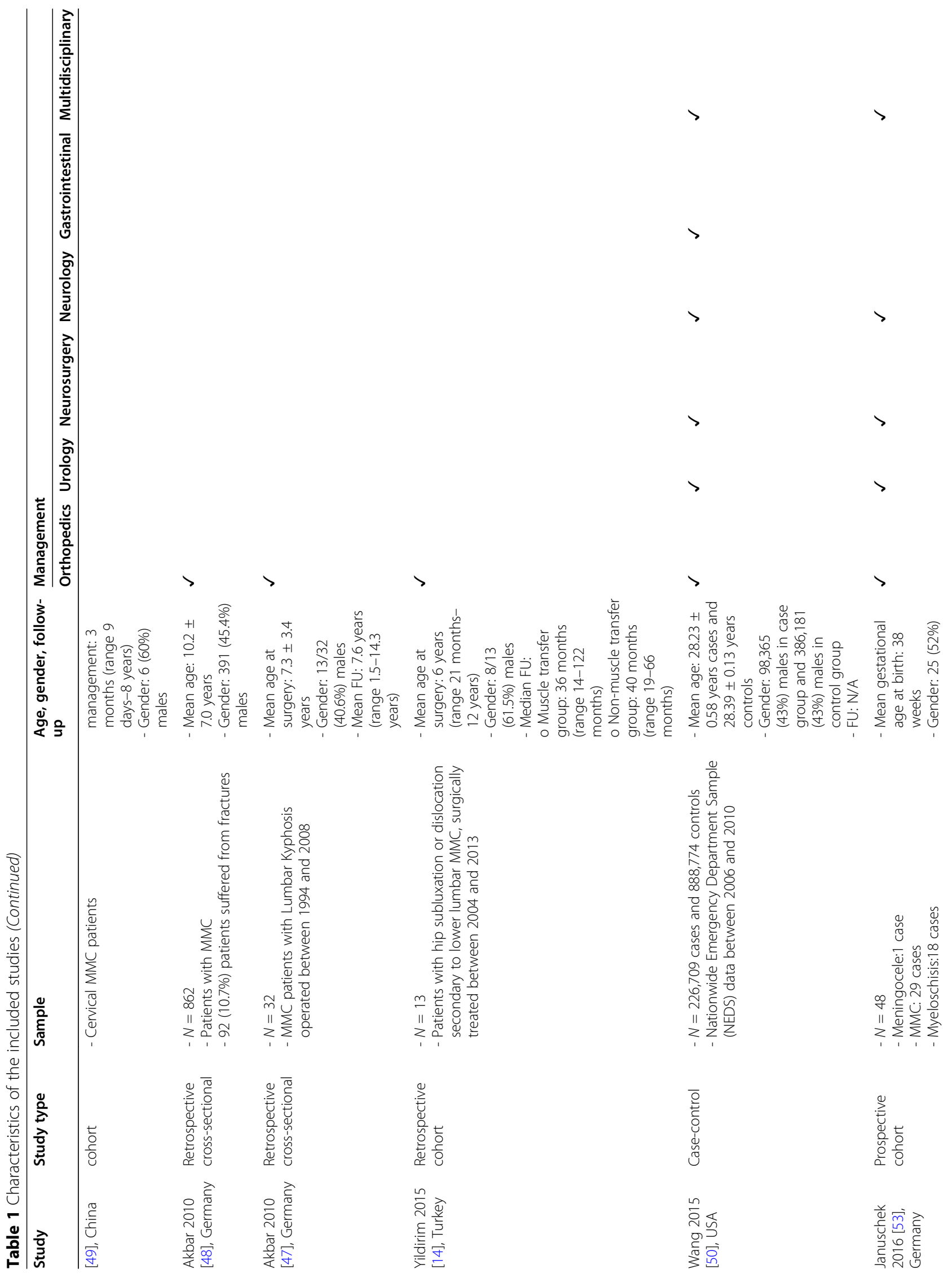




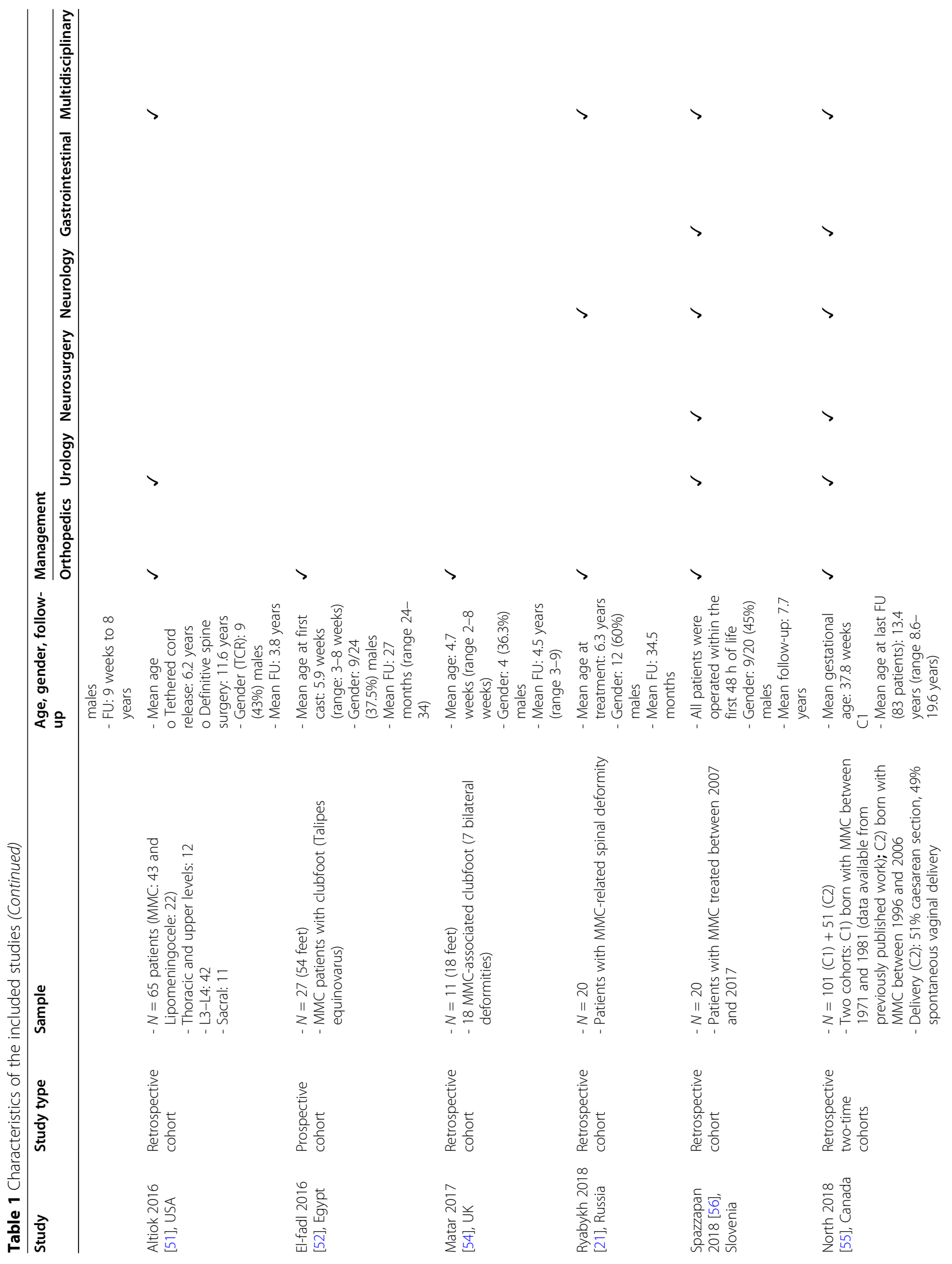




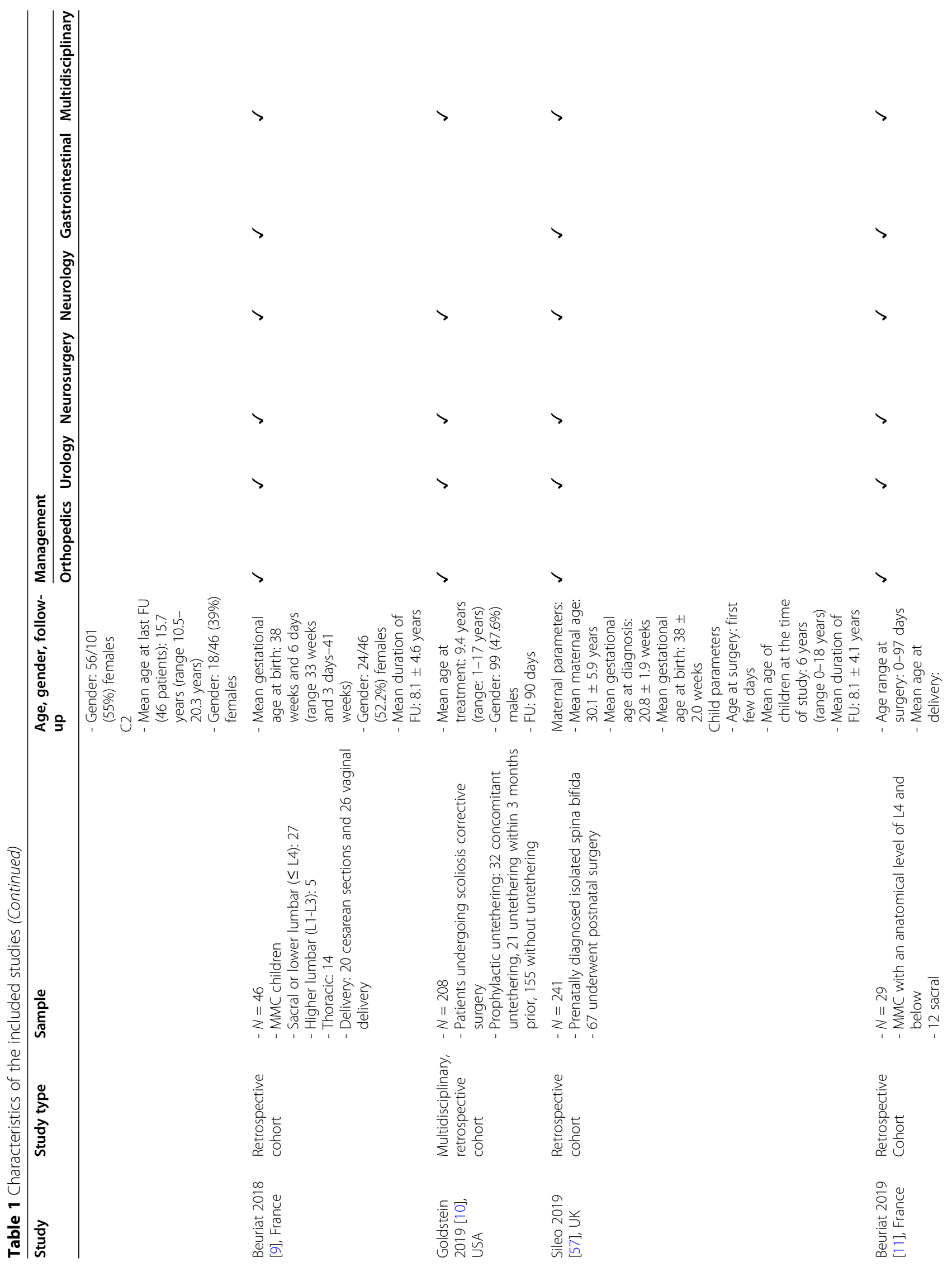




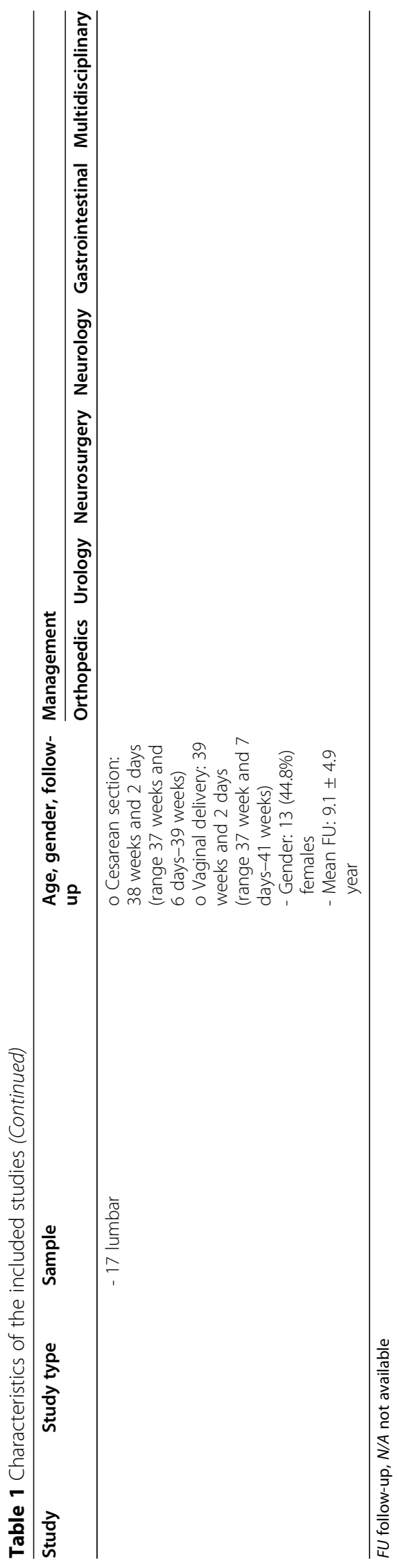


Table 2 Newcastle-Ottawa Scale (NOS) risk of bias assessment of the included studies

\begin{tabular}{|c|c|c|c|c|}
\hline Author, year & $\begin{array}{l}\text { Selection } \\
(0-4)\end{array}$ & Comparability (0-2) & Exposure/outcome (0-3) & $\begin{array}{l}\text { Total score } \\
(0-9)\end{array}$ \\
\hline Torosian 2000 [42] & 3 & 1 & 2 & 6 \\
\hline Sponseller 2000 [41] & 2 & 2 & 3 & 7 \\
\hline Frischhut 2000 [12] & 3 & 0 & 3 & 6 \\
\hline Parsch 2001 [13] & 3 & 0 & 2 & 5 \\
\hline Crawford 2003 [20] & 3 & 0 & 3 & 6 \\
\hline Ozerdemoglu 2003 [43] & 4 & 0 & 3 & 7 \\
\hline Ulsenheimer 2004 [44] & 3 & 0 & 3 & 6 \\
\hline Erol 2005 [26] & 3 & 0 & 3 & 6 \\
\hline Lemelle 2006 [45] & 4 & 0 & 3 & 7 \\
\hline Gerlach 2009 [46] & 4 & 2 & 3 & 9 \\
\hline Huang 2010 [49] & 3 & 0 & 3 & 6 \\
\hline Akbar 2010 [48] & 4 & 0 & 3 & 7 \\
\hline Akbar 2010 [47] & 3 & 0 & 3 & 6 \\
\hline Yildirim 2015 [14] & 4 & 1 & 3 & 8 \\
\hline Wang 2015 [50] & 4 & 2 & 3 & 9 \\
\hline Januschek 2016 [53] & 3 & 0 & 2 & 5 \\
\hline Altiok 2016 [51] & 3 & 0 & 3 & 6 \\
\hline El-Fadl 2016 [52] & 3 & 0 & 3 & 6 \\
\hline Matar 2017 [54] & 3 & 0 & 3 & 6 \\
\hline Ryabykh 2018 [21] & 3 & 0 & 3 & 6 \\
\hline Spazzapan 2018 [56] & 3 & 0 & 3 & 6 \\
\hline North 2018 [55] & 4 & 0 & 3 & 7 \\
\hline Beuriat 2018 [9] & 3 & 0 & 3 & 6 \\
\hline Goldstein 2019 [10] & 4 & 1 & 3 & 8 \\
\hline Sileo 2019 [57] & 3 & 0 & 3 & 6 \\
\hline Beuriat 2019 [11] & 4 & 0 & 3 & 7 \\
\hline
\end{tabular}

L3-L4, and 24 with L5-sacral lesions) to 19 cases at 10 years (9 with T12-L2, 8 with L3-L4, and 2 with L5-sacral lesions). At the last follow-up visit (24.5 years on average), in patients with L5-sacral lesions, the calcaneus deformity had increased again up to 16 cases [12].

\section{Spine}

Ten out of the 26 included studies included corrective operations of the spine related to scoliosis in 5 studies $[10,13,21,43,51]$, kyphosis in 3 studies [20, 21, 47], and lumbar lordosis in 2 studies [20,21].

Scoliosis Parsch et al. reported three surgical techniques: (I) posterior fusion (Cotrel-Dubousset instrumentation or Spine-Fix system) $(n=20)$, (II) anterior osteodiscectomy + posterior fusion $(n=12)$, and (III) anterior ventral derotational spondylodesis (VDS) + posterior fusion $(n=22)$ [13]. They measured the postoperative Cobb angle (median-IQR) for each group: (I) $35^{\circ}$ $\left(23^{\circ}-49^{\circ}\right)$, (II) $52^{\circ}\left(37^{\circ}-65^{\circ}\right)$, and (III) $38^{\circ}\left(30^{\circ}-40^{\circ}\right)$. The median-IQR for the loss of correction of scoliosis in each group was (I) $9^{\circ}\left(-2^{\circ}-52^{\circ}\right)$, (II) $10^{\circ}\left(1^{\circ}-52^{\circ}\right)$, and (III) $7^{\circ}\left(0^{\circ}-26^{\circ}\right)$. They reported that VDS combined with posterior fusion has resulted in a better midterm correction of scoliosis compared with posterior fusion alone $(P$ $=0.02$ ). Also, thoracic level paralysis had a more negative impact on the relative loss of correction compared with the lumbar level paralysis. They recommended the two-stage procedure in patients with a thoracic level of paralysis to reduce the risk of hardware complications and loss of correction [13].

Ozerdemoglu et al. indicated nonoperative treatment (passive observation and/or bracing) in $18 \mathrm{MMC}$ patients and reported a curve progression of $3.4^{\circ}$ per year [43]. Altiok et al. performed tethered cord release surgery (TCR) before scoliosis surgery. The average Cobb angle improved from $68.4^{\circ} \pm 21.8^{\circ}$ before TCR to $44.5^{\circ} \pm$ $16.6^{\circ}$ after corrective spine surgery [51]. Ryabykh et al. 
reviewed the outcome of instrumented fusion by pedicle screw-rod constructs in 20 patients. The preoperative mean Cobb angle for scoliosis was $36.7^{\circ}$ (median: $36^{\circ}$, range $11^{\circ}-77^{\circ}$ ) and the mean Cobb angle scoliosis correction was $25^{\circ}$ (median $23^{\circ}$, range $1^{\circ}-62^{\circ}$ ) [21]. Goldstein et al. used prophylactic spinal cord untethering within 3 months prior $(N=21)$ or concomitant $(N=32)$ with the corrective scoliosis surgery in MMC patients. They found an increased risk of complications, including surgical site infection (adjusted $\mathrm{RR}=2.65, p=0.02$ ), rate of return to operation room (adjusted $\mathrm{RR}=2.17, p=$ $0.045)$, the need for blood transfusion $(p=0.04)$, and increased mean length of stay $(p<0.0001)$. Moreover, they stated no increased risk of neurological injury without prophylactic untethering before scoliosis surgery in MMC patients [10].

Kyphosis Crawford et al. investigated the effect of kyphectomy in combination with dural sac closure on 11 neonates [20]. They reported an average preoperative kyphotic angle of $67^{\circ}$, an average initial correction of $77^{\circ}$, and an average loss of correction of $55^{\circ}$ at follow-up. Of the nine patients who were available for long-term radiographic follow-up (7 years and 4 months on average), four patients had kyphosis less than $67^{\circ}$ (range $4^{\circ}-$ $67^{\circ}$ ), and three had kyphosis greater than $100^{\circ}$ (range $100^{\circ}-103^{\circ}$ ). Although their surgical management proved to be safe and led to satisfactory initial correction, it showed a high recurrence of deformity [20]. In the study conducted by Ryabykh et al., the preoperative Cobb angle for kyphosis was $83.7^{\circ}$ (median $75^{\circ}$, range $45^{\circ}-$ $\left.134^{\circ}\right)$ and the mean kyphosis correction angle was $57^{\circ}$ (median $56^{\circ}$, range $19^{\circ}-96^{\circ}$ ) [21]. Akbar et al. conducted Gibbus surgery and postoperative rehabilitation. The mean preoperative lumbar kyphosis angle was $131^{\circ}\left(90^{\circ}-\right.$ $\left.170^{\circ}\right)$, and the mean postoperative kyphosis correction angle was $42^{\circ}\left(15^{\circ}-90^{\circ}\right)$ [47].

Lumbar lordosis In the study of Ryabykh et al., only four patients needed lordosis correction [21]. The mean preoperative Cobb angle for lordosis was 67 (median $71^{\circ}$, range $43^{\circ}-84^{\circ}$ ) and the mean postoperative Cobb angle correction was $25^{\circ}$ (median $28^{\circ}$; range $9^{\circ}-35^{\circ}$ ) [21]. Crawford et al. reported five patients with an average postoperative lordosis of $34^{\circ}$ (range $9-52^{\circ}$ ) after the initial correction, two of which retained the lordosis $\left(5^{\circ}\right.$ and $27^{\circ}$ ) during the long-term follow-up [20].

\section{Hip}

Two studies attempted to manage hip instabilities surgically $[14,26]$. Erol et al. conducted open reduction, pelvic osteotomy, proximal femoral osteotomy, and release for hip flexion contracture on 26 MMC patients with hip instabilities [26]. Of the 16 patients with unilateral dislocation and functional problems, 14 experienced improvements in gait patterns, while the other did not show any improvement [26]. Yildirim et al. evaluated the periarticular release of contractures and bony procedures, with or without muscle transfer in two groups [14]. According to Reimer's radiographic index, the residual subluxation of the femoral head did not differ between the two groups. Despite the overall improvement of the pelvic obliquity, these two groups did not demonstrate any significant difference. The postoperative assessment showed that functional ambulatory remained similar to the preoperative status [26].

\section{Multidisciplinary management}

Sixteen studies [9-12, 20, 21, 43-45, 49-51, 53, 55-57] had used managements other than orthopedic, including urologic, neurosurgical, neurologic, and gastrointestinal managements.

\section{Urologic management}

Wang et al. reported that compared to controls, SB patients required more urologic procedures $(0.56 \%$ cases vs. $0.13 \%$ controls, $\mathrm{OR}=4.4, p<0.001$ ] [50]. Lemelle et al. managed incontinency either with medical (191 patients) or surgical (230 patients) approaches [45]. The clean intermittent catheterization (CIC) was used by 116 (61\%) patients in the medical treatment group. Surgical interventions included urinary non-continent diversion (Bricker procedure in 19 and vesicostomy in 4 patients), intestinal bladder augmentation (148 patients), bladder neck surgery (49 patients), detrusorotomy (4 patients), and neurostimulation (6 patients).

In a single institute analysis, Januschek et al. reported that $\mathrm{CIC}$ was the most common management for damaged bladder [53]. However, they had a case of urogenito-ano-rectal malformation, which required colostomy and suprapubic vesical fistula. Despite releasing untethered cord procedures, Altiok et al. reported bladder control impairment [51]. According to the study by Goldstein et al., prophylactic spinal cord untethering before scoliosis correction surgeries improved the urologic function of $1 \%$ of the MMC patients, which is not promising [10]. Sileo et al. indicated postnatal surgical repairs on neonates with MMC, $10.9 \%$ of whom were diagnosed with hydronephrosis at the follow-up, and $81.8 \%$ with a neuropathic bladder [57]. To alleviate the complications, CIC (85.5\%) and anticholinergic pharmacological therapies $(87.3 \%)$ were used. Moreover, $89.1 \%$ of the infants had different levels of urinary incontinence. Two studies of Beuriat et al. $[9,11]$ utilized postoperative bladder managements on average as follows: non-autonomous natural rout CIC (21.74-7\%), autonomous natural rout CIC (21.74-33\%), non-autonomous Mitrofanoff CIC (10.87-7\%), autonomous Mitrofanoff CIC (6.52-7\%), 
and diapers (26.09-23\%) published in 2018 and 2019, respectively. Spazzapan and his colleagues followed the treated MMC children for a mean of 7.7 years and found that $21 \%$ of the patients had normal bladder function, $5.2 \%$ were suffering from incontinency, and $73.6 \%$ were having neurogenic bladder [56].

Moreover, they showed that urinary dysfunction and MMC level are not significantly correlated $(p=0.062)$. North et al. performed two 10-year cohorts and reported that $82 \%$ of patients in the first cohort and $94 \%$ of patients in the second cohort benefited from CIC to manage incontinency [55]. In the study from Ulsenheimer et al., seven patients required $\mathrm{CIC}$ based on the vesicourethral reflux or significant vesicle residues [44]. Anticholinergic medications was needed for seven patients. They also prescribed a combination of doxozym with oxybutynin for one patient and a combination of imypramine and oxybutynin for another one. Repeated urinary tract infections (UTI) episodes were reported in 10 patients. Also, they prescribed prophylactic antibiotics for all patients with neurogenic bladder [44].

\section{Neurosurgical and neurological management}

The follow-up assessments of kyphosis corrective surgery in the study of Ryabykh et al. showed improvement of modified Japanese Orthopedic Association (mJOA) neurologic scale by 0.6 points and the functional independence measure (FIM score) by 6.6 points, which represents average functional status [21]. None of the patients suffered from back pain (visual analog scale $=$ 0 ). The requirement of ventriculoperitoneal (VP) shunt revision ranged from 30.5 to $86 \%$ in different studies [30, $39,42,44]$. In the study conducted by Ozerdemoglu et al., 16 out of the $26 \mathrm{MMC}$ patients required a spinal fusion ultimately [43].

\section{Gastrointestinal management}

Bowel management in patients suffering from MMC consists of two main categories; enema and diapers. Two studies by Beuriat et al. $[9,11]$ reported the rate of using enema as $(34.78-24 \%)$ and diapers as $(30.43-21 \%)$ published in 2018 and 2019, respectively. Applying suppositories, cecostomy tubes, digital sweeps, oral medication, diet control, and antegrade colonic enema (ACE) are other proposed management $[55,57]$. Spazzapan et al. used colostomy in $5.2 \%$ of patients to manage bowel incontinency [56].

\section{Discussion}

This review is the first to summarize outcomes and applications of various multidisciplinary orthopedic, urologic, neurologic, and gastrointestinal management of patients with MMC with an orthopedic focus. The orthopedic management of MMC tends to be based on musculoskeletal problems. MMC patients encounter congenital and acquired deformities, which can affect their quality of life. Congenital deformities include scoliosis, kyphosis, teratological hip dislocations, club feet, and flat feet with vertical talus.

Collectively, for MMC patients with mild to moderate scoliosis (a flexible curve $<50^{\circ}$ ), non-operative treatment is suggested (e.g., sitting supports, spinal orthoses, and functional strengthening programs) to help them improve their independent functions [22, 61]. However, for MMC patients with severe scoliosis, the treatment plan is based on whether they are ambulatory or not. Orthopedists mainly offer surgical treatment for nonambulatory patients who suffer from sitting or skin deformities due to spine curvature [25, 62]. Regarding ambulatory patients, surgeons must decide case by case and consider the pros and cons of surgical intervention, mainly spinal fusion $[25,62,63]$. Possible complications are implant problems [64] (e.g., implant failure, dislocation, and pseudoarthrosis [25]) and wound infections [25].

Considering hip deformities, maintaining hip range of motion should be the orthopedist's treatment goal. Formerly, most hip surgical interventions were performed to reduce paralytic hip dislocations, but they were not successful in achieving the ability to ambulate, lessening the need for bracing, or relieving pain [27-29, 65]. In contrast, currently, hip surgeries aim to release contractures. It is worth mentioning that treatment plan varies based on the level of myelomeningocele, whether sacral-level or thoracic and lumbar-level. Ultimately, surgeons should consider that maintaining a level pelvis and free motion of the hips rather than radiographic reduction of the hip are primary goals of the treatment plan [28]. Additionally, loss of motion and pathologic fractures are among surgical complications hindering ambulation $[28,29]$.

As torsional abnormalities of the lower extremities often occur in MMC patients, it is essential to manage them if it interferes with their gait and ambulation. For non-ambulatory patients, orthopedic surgeon aims to minimize bracing requirements while achieving as normal a gait as possible. It is generally suggested to delay the surgery until the patient is 6 years old to decrease the risk of recurrence, and till then, orthotic management is helpful to maintain gait function [66]. Rotational osteotomy is the foremost choice of surgery in case of severity and difficulty with orthoses [67].

Regarding foot and ankle issues management, the orthopedist's treatment goal includes a plantigrade, flexible, braceable foot on which a shoe can be worn to allow ambulation. Conservative management with passive manipulation is mainly offered for MMC patients with equinus, calcaneus, and mild positional clubfoot. 
For instance, severe clubfoot deformities may require surgical correction following the radical posteromediallateral release (PMLR) method, which leads to controversial outcomes due to the motor level of involvement [68]. Calcaneous feet treatment was reported following the anterior or anterolateral soft-tissue release with an $82 \%$ success rate [69]. Distal tibia valgus deformity could be corrected by medial hemiepiphysiodesis of the distal tibia or, in severe cases, distal tibia osteotomy. For hindfoot valgus, treatment consists of a medial displacement osteotomy of the calcaneus [18].

In children with $\mathrm{MMC}$, orthoses are used to maintain alignment, prevent deformity, correct flexible deformities, facilitate independent mobility, and protect the insensate limb. Orthoses are used for upright weightbearing and mobility in thoracic and lumbar MMC patients. Due to absent hip extensors and abductors and ankle plantar- and dorsi-flexors, orthoses could help MMC patients with low lumbar and sacral level involvement $\mathrm{s}[70]$.

The majority of the included studies performed postnatal management and operations rather than prenatal. Although controversies exist between surgeons, postnatal repair is established as a worldwide standard for MMC patients [71]. Concurrently, the MOMS (the management of myelomeningocele study) has indicated that prenatal repair increased maternal and fetal complication risks. The outcomes were significantly better than postnatal repair in decreasing the need for VP shunt and hydrocephalus occurrence ( $40 \%$ vs. $82 \%$ ), as well as functional improvement. The MOMS cohort assessed gait independence at the age of 30 months. As a result, more of the prenatal group had independent gait versus postnatal ( $40 \%$ vs. $21 \%$ ) [72]. Prenatal repair of MMC is categorized as the neurosurgical management of MMC. We should consider the delivery method (cesarean section or vaginal delivery) to secure the neonate, neural tissues, and MMC sac [71]. However, Greene et al. reported no significant difference between the mode of delivery (cesarean and vaginal delivery) and patients' motor functions [73]. Regarding urological complications, MMC patients undergoing fetal (prenatal) surgery require neurogenic bladder management, similar to patients experiencing postnatal surgeries [74].

Ambulation status is one of the features taken into account for assessing the efficacy and effectiveness of the conducted procedures. The ambulation status is influenced by spasticity, contractures, syringohydromyelia, and musculoskeletal problems including, foot, knee, and hip deformities and scoliosis. Moreover, it has been suggested that the neurologic impairment level is a significant factor for ambulation. Although shunting is widely used as prenatal management, the history of shunt insertion or revision has a negative effect on ambulation status [75-77]. In the orthopedic field, surgeons correct spinal deformities to support muscle balance and sitting stability. Also, orthopedists can release hamstrings and treat knee flexion contractures in ambulatory patients. The valgus deformity can also affect ambulation due to muscle imbalance [78]. Although utilizing assistive devices may decrease the number of steps per day, it is a positive factor for predicting walking activity in MMC [79].

Shreds of evidence show that untethering the spinal cord prior to scoliosis surgery may be redundant in patients who do not characterize symptoms (e.g., pain, weakness, gait abnormality, lower extremity, hip and foot deformity, urological changes, and rapidly progressive scoliosis) [80].

Pediatric urologists' experience confirms that clean intermittent catheterization (CIC) may lessen renal deterioration risk. Moreover, in some cases, CIC might be influential on renal function improvement. The success rate of the CIC program hinges on several factors (e.g., physiological, developmental, motivational) [81].

The ultimate aim of management in MMC patients is to improve their quality of life. To assess the quality of life, there is a controversy regarding the person who should take the survey: the patients, their parents, or both. Studies measuring patients' health status with MMC have reported a lower health-related quality of life (HRQOL) than the general population [82-85]. On the other hand, exercise and fitness showed an essential impact on higher HRQOL [86]. Some studies have introduced predictors for HRQOL, including the need for support and an assistant to supervise them. In contrast, lesion level and social status had no significant effect on overall HRQOL [82]. Besides, managements like bladder augmentation increased patients' HRQOL by reducing the need for catheterization [87].

Despite all efforts for the management of MMC, it should be noted that lesser the time we waste, the better outcome we can achieve. Therefore, more equipped multidisciplinary centers should be established to give MMC patients the care and management they need and help them acquire a better quality of life. This approach brings together patients and specialists experienced in different disciplines. Moreover, the modern world has introduced robotic-assisted surgeries in the medical community, which could help surgeons accomplish better outcomes and reduce surgical complications. It is also suggested to conduct more studies on prenatal repair surgeries to compare their application, outcomes, and complications with postnatal repair surgeries.

This study encountered several limitations. We did not comprehensively review managements other than orthopedics due to the specific focus of our study. Included studies were mainly retrospective analyses rather 
than RCTs, which are critically needed to achieve more robust results. Another limitation of this study was that included studies did not have a homogeneous size of samples and surgery techniques. Further multivariate analyses are required to reveal each management's effects on MMC patients' HRQOL.

\section{Conclusion}

Timely and proper multidisciplinary management is critical for MMC given its high burden and psychosocial consequences. Orthopedic approaches play a key role in MMC management by alleviating spinal deformities, particularly scoliosis, and hip, foot, and ankle complications. However, the most appropriate management, whether surgical or non-surgical, may vary for different patients, given disease severity and the age of patients.

\section{Abbreviations \\ ACE: Antegrade colonic enema; CIC: Clean intermittent catheterization; EUROCAT: European Surveillance of Congenital Anomalies; FIM: Functional independence measure; HRQOL: Health-related quality of life; \\ mJOA: Modified Japanese Orthopedic Association; MMC: Myelomeningocele; MOMS: The management of myelomeningocele study; NTD: Neural tube defect; SB: Spina bifida; TCR: Tethered cord release surgery; UTI: Urinary tract infection; VDS: Ventral derotational spondylodesis; VP: Ventriculoperitoneal}

\section{Acknowledgements}

Not applicable

\section{Authors' contributions}

PS: drafting of the manuscript/study conception and design/data acquisition/analysis and data interpretation. AP critical revision. AK: data acquisition/analysis and data interpretation/critical revision. SM: data acquisition/critical revision. FV: critical revision. MHN: study conception and design/critical revision. All authors read and approved the final manuscript.

\section{Funding}

None declared.

\section{Availability of data and materials \\ Not applicable}

\section{Declarations}

Ethics approval and consent to participate

Not applicable

\section{Consent for publication}

Not applicable

\section{Competing interests}

The authors declare that they have no competing interests.

\section{Author details}

'School of Medicine, Tehran University of Medical Sciences (TUMS), Tehran, Iran. ${ }^{2}$ Universal Scientific Education and Research Network (USERN), Tehran, Iran. ${ }^{3}$ Non-Communicable Diseases Research Center, Endocrinology and Metabolism Population Sciences Institute, Tehran University of Medical Sciences, Tehran, Iran. ${ }^{4}$ Department of Pediatric Orthopedics, Hôpital Robert Debre, Paris, France. ${ }^{5}$ Department of Orthopedic and trauma surgery, Shariati Hospital and School of Medicine, Tehran University of Medical Sciences (TUMS), Tehran, Iran. ${ }^{6}$ Center of Orthopedic Trans-Disciplinary Applied Research (COTAR), Tehran University of Medical Sciences (TUMS), Tehran, Iran
Received: 16 June 2021 Accepted: 28 July 2021

Published online: 13 August 2021

\section{References}

1. Copp AJ, Adzick NS, Chitty LS, Fletcher JM, Holmbeck GN, Shaw GM. Spina bifida. Nat Rev Dis Primers. 2015;1:15007.

2. Russo CA, Elixhauser A. Hospitalizations for birth defects, 2004: Statistical Brief \#24. Healthcare Cost and Utilization Project (HCUP) Statistical Briefs. Rockville (MD): Agency for Healthcare Research and Quality (US); 2006.

3. Dolk H, Loane M, Garne E. The prevalence of congenital anomalies in Europe. Adv Experiment Med Biol. 2010;686:349-64.

4. Meuli M, Meuli-Simmen C, Hutchins GM, Seller MJ, Harrison MR, Adzick NS. The spinal cord lesion in human fetuses with myelomeningocele: implications for fetal surgery. J Pediatr Surg. 1997;32(3):448-52.

5. McCarthy DJ, Sheinberg DL, Luther E, McCrea HJ. Myelomeningoceleassociated hydrocephalus: nationwide analysis and systematic review. Neurosurg Focus. 2019;47(4):E5

6. Dyste GN, Menezes AH, VanGilder JC. Symptomatic Chiari malformations. An analysis of presentation, management, and long-term outcome. J Neurosurg. 1989;71(2):159-68.

7. Hoffman HJ, Hendrick EB, Humphreys RP. Manifestations and management of Arnold-Chiari malformation in patients with myelomeningocele. Child's brain. 1975;1(4):255-9.

8. Talamonti G, Marcati E, Mastino L, Meccariello G, Picano M, D'Aliberti G. Surgical management of Chiari malformation type II. Childs Nerv Syst. 2020; 36(8):1621-34

9. Beuriat PA, Poirot I, Hameury F, Szathmari A, Rousselle C, Sabatier I, et al. Postnatal management of myelomeningocele: outcome with a multidisciplinary team experience. World Neurosurgery. 2018;110:e24-31.

10. Goldstein HE, Shao B, Madsen PJ, Hartnett SM, Blount JP, Brockmeyer DL, et al. Increased complications without neurological benefit are associated with prophylactic spinal cord untethering prior to scoliosis surgery in children with myelomeningocele. Childs Nerv Syst. 2019;35(11):2187-94.

11. Beuriat PA, Poirot I, Hameury F, Demede D, Sweeney KJ, Szathmari A, et al. Low level myelomeningoceles: do they need prenatal surgery? Child's Nervous System. 2019

12. Frischhut B, Stöckl B, Landauer F, Krismer M, Menardi G. Foot deformities in adolescents and young adults with spina bifida. J Pediatr Orthop B. 2000; 9(3):161-9.

13. Parsch D, Geiger F, Brocai DR, Lang RD, Carstens C. Surgical management of paralytic scoliosis in myelomeningocele. J Pediatr Orthop B. 2001:10(1):10-7.

14. Yildirim T, Gursu S, Bayhan IA, Sofu H, Bursali A. Surgical Treatment of Hip Instability in Patients With Lower Lumbar Level Myelomeningocele: Is Muscle Transfer Required? Clin Orthop Relat Res. 2015;473(10):3254-60.

15. Westcott MA, Dynes MC, Remer EM, Donaldson JS, Dias LS. Congenital and acquired orthopedic abnormalities in patients with myelomeningocele. Radiographics. 1992;12(6):1155-73.

16. Swaroop VT, Dias L. Orthopaedic management of spina bifida-part II: foot and ankle deformities. J Children's Orthopaedics. 2011;5(6):403-14.

17. Lubicky JP, Altiok H. Transphyseal osteotomy of the distal tibia for correction of valgus/varus deformities of the ankle. J Pediatr Orthop. 2001 21(1):80-8.

18. Sharrard WJ, Grosfield I. The management of deformity and paralysis of the foot in myelomeningocele. J Bone Joint Surg Br. 1968;50(3):456-65.

19. Roach JW, Short BF, Saltzman HM. Adult consequences of spina bifida: a cohort study. Clin Orthop Relat Res. 2011:469(5):1246-52.

20. Crawford AH, Strub WM, Lewis R, Gabriel KR, Billmire DA, Berger T, et al. Neonatal kyphectomy in the patient with myelomeningocele. Spine. 2003: 28(3):260-6.

21. Ryabykh SO, Pavlova OM, Savin DM, Burtsev AV, Gubin AV. Surgical Management of Myelomeningocele-Related Spinal Deformities. World Neurosurg. 2018;112:e431-e41.

22. Berven S, Bradford DS. Neuromuscular scoliosis: causes of deformity and principles for evaluation and management. Semin Neurol. 2002;22(2):16778.

23. Schoenmakers MA, Gulmans VA, Gooskens RH, Pruijs JE, Helders PJ. Spinal fusion in children with spina bifida: influence on ambulation level and functional abilities. Eur Spine J. 2005;14(4):415-22.

24. Wai EK, Young NL, Feldman BM, Badley EM, Wright JG. The relationship between function, self-perception, and spinal deformity: Implications for 
treatment of scoliosis in children with spina bifida. J Pediatr Orthop. 2005; 25(1):64-9.

25. Guille JT, Sarwark JF, Sherk HH, Kumar SJ. Congenital and developmental deformities of the spine in children with myelomeningocele. J Am Acad Orthop Surg. 2006;14(5):294-302.

26. Erol B, Bezer M, Küçükdurmaz F, Güven O. Surgical management of hip instabilities in children with spina bifida. Acta Orthop Traumatol Turc. 2005; 39(1):16-22.

27. Gabrieli AP, Vankoski SJ, Dias LS, Milani C, Lourenco A, Filho JL, et al. Gait analysis in low lumbar myelomeningocele patients with unilateral hip dislocation or subluxation. J Pediatr Orthop. 2003;23(3):330-4.

28. Feiwell E, Sakai D, Blatt T. The effect of hip reduction on function in patients with myelomeningocele. Potential gains and hazards of surgical treatment. J Bone Joint Surg Am. 1978;60(2):169-73.

29. Sherk HH, Uppal GS, Lane G, Melchionni J. Treatment versus non-treatment of hip dislocations in ambulatory patients with myelomeningocele. Dev Med Child Neurol. 1991;33(6):491-4.

30. Greggi T, Lolli F, Di Silvestre M, Martikos K, Vommaro F, Maredi E, et al. Surgical treatment of neuromuscular scoliosis: current techniques. Stud Health Technol Inform. 2012;176:315-8.

31. Kabagambe SK, Jensen GW, Chen YJ, Vanover MA, Farmer DL. Fetal surgery for myelomeningocele: a systematic review and meta-analysis of outcomes in fetoscopic versus open repair. Fetal Diagn Ther. 2018:43(3):161-74.

32. Mazzone L, Hölscher AC, Moehrlen U, Gobet R, Meuli M, Horst M. Urological outcome after fetal spina bifida repair: data from the Zurich Cohort. Fetal Diagn Ther. 2020:1-7.

33. Taşkapılıoğlu MÖ, Türedi B, Altunyuva O, Utanğaç MM, Balkan ME, Klıç N. Retrospective analysis of early-and late-operated meningomyelocele patients. Child's Nervous System. 2021;37(2):539-43.

34. Bendt M, Gabrielsson H, Riedel D, Hagman G, Hultling C, Franzén E, et al. Adults with spina bifida: a cross-sectional study of health issues and living conditions. Brain Behavior. 2020;10(8):e01736.

35. Farmer DL, Thom EA, Brock JW, 3rd, Burrows PK, Johnson MP, Howell LJ, et al. The management of myelomeningocele study: full cohort 30-month pediatric outcomes. Am J Obstet Gynecol. 2018;218(2):256.e1-13.

36. Franks CA, Palisano RJ, Darbee JC. The effect of walking with an assistive device and using a wheelchair on school performance in students with myelomeningocele. Physical therapy. 1991;71(8):570-7 discussion 7-9.

37. Lullo B, Mueske N, Diamant C, Van Speybroeck A, Ryan D, Wren T. Predictors of Walking Activity in Children and Adolescents With Myelomeningocele. Arch Phys Med Rehabil. 2020;101(3):450-6.

38. Page MJ, MCKenzie JE, Bossuyt PM, Boutron I, Hoffmann TC, Mulrow CD, et al. The PRISMA 2020 statement: an updated guideline for reporting systematic reviews. Systematic Reviews. 2021;10(1):89.

39. Shobeiri P KA, Momtazmanesh S, Vosoughi F, Nabian MH A systematic review on multidisciplinary management of Myelomeningocele focusing on Orthopedics: application, outcomes, and complications. PROSPERO 2021 CRD42021225916 2021 [Available from: https://www.crd.york.ac.uk/ prospero/display_record.php?ID=CRD42021225916.

40. Moher D, Liberati A. A., Tetzlaff, J., \& Altman, DG (2009). Preferred reporting items for systematic reviews and meta-analyses: the PRISMA statement. BMJ. 339:b2535.

41. Sponseller PD, LaPorte DM, Hungerford MW, Eck K, Bridwell KH, Lenke LG. Deep wound infections after neuromuscular scoliosis surgery: a multicenter study of risk factors and treatment outcomes. Spine (Phila Pa 1976). 2000; 25(19):2461-6.

42. Torosian CM, Dias LS. Surgical treatment of severe hindfoot valgus by medial displacement osteotomy of the os calcis in children with myelomeningocele. J Pediatr Orthop. 2000;20(2):226-9.

43. Ozerdemoglu RA, Transfeldt EE, Denis F. Value of treating primary causes of syrinx in scoliosis associated with syringomyelia. Spine (Phila Pa 1976). 2003; 28(8):806-14.

44. Ulsenheimer MMM, Antoniuk SA, Dos Santos LHC, Ceccatto MP, Da Silveira AE, Ruiz AP, et al. Myelomeningocele: A Brazilian University Hospital experience. Arquivos de Neuro-Psiquiatria. 2004;62(4):963-8.

45. Lemelle JL, Guillemin F, Aubert D, Guys JM, Lottmann H, Lortat-Jacob S, et al. A multicenter evaluation of urinary incontinence management and outcome in spina bifida. Journal of Urology. 2006;175(1):208-12.

46. Gerlach DJ, Gurnett CA, Limpaphayom N, Alaee F, Zhang Z, Porter K, et al. Early results of the Ponseti method for the treatment of clubfoot associated with myelomeningocele. J Bone Joint Surg Am. 2009;91(6):1350-9.
47. Akbar M, Almatrod S, Fürstenberg CH, Hemmer S, Kretzer JP, Abel R, et al. Kyphectomy in myelomeningocele patients. Longterm results, complications and risk analysis. Orthopade. 2010;39(8):792-800.

48. Akbar M, Bresch B, Raiss $P$, Fürstenberg $C H$, Bruckner T, Seyler T, et al. Fractures in myelomeningocele. J Orthop Traumatol. 2010;11(3):175-82.

49. Huang SL, Shi W, Zhang LG. Characteristics and surgery of cervical myelomeningocele. Child's Nervous System. 2010;26(1):87-91.

50. Wang HHS, Wiener JS, Ross SS, Routh JC. Emergent care patterns in patients with spina bifida: a case-control study. J Urol. 2015;193(1):268-73.

51. Altiok H, Riordan A, Graf A, Krzak J, Hassani S. Response of scoliosis in children with myelomeningocele to surgical release of tethered spinal cord. Top Spinal Cord Inj Rehabil. 2016;22(4):247-52.

52. El-Fadl SA, Sallam A, Abdelbadie A. Early management of neurologic clubfoot using Ponseti casting with minor posterior release in myelomeningocele: a preliminary report. J Pediatric Orthopaedics Part B. 2016;25(2):104-7.

53. Januschek E, Röhrig A, Kunze S, Fremerey C, Wiebe B, Messing-Jünger M. Myelomeningocele - a single institute analysis of the years 2007 to 2015. Child's Nervous System. 2016;32(7):1281-7.

54. Matar HE, Beirne P, Garg NK. Effectiveness of the Ponseti method for treating clubfoot associated with myelomeningocele: 3-9 years follow-up. J Pediatr Orthop B. 2017;26(2):133-6.

55. North T, Cheong A, Steinbok P, Radic JA. Trends in incidence and long-term outcomes of myelomeningocele in British Columbia. Child's Nervous System. 2018;34(4):717-24.

56. Spazzapan P, Velnar T. Myelomeningocele in slovenia: results of a 10 years follow-up. J Neurosurg Sci. 2018.

57. Sileo FG, Pateisky P, Curado J, Evans K, Hettige S, Thilaganathan B. Longterm neuroimaging and neurological outcome of fetal spina bifida aperta after postnatal surgical repair. Ultrasound Obstetrics Gynecol. 2019;53(3): 309-13.

58. Biedermann R. Orthopedic management of spina bifida. Der Orthopäde. 2014:43(7):603-10.

59. Diméglio A, Bensahel H, Souchet P, Mazeau P, Bonnet F. Classification of clubfoot. J Pediatr Orthop B. 1995;4(2):129-36.

60. Horn A, Dix-Peek S, Mears S, Hoffman EB. The orthopaedic management of myelomeningocele. South African Med J. 2014;104(4):314.

61. McCarthy RE. Management of neuromuscular scoliosis. Orthop Clin North Am. 1999;30(3):435-49 viii.

62. Mazur J, Menelaus MB, Dickens DR, Doig WG. Efficacy of surgical management for scoliosis in myelomeningocele: correction of deformity and alteration of functional status. J Pediatr Orthop. 1986;6(5):568-75.

63. Müller EB, Nordwall A, von Wendt L. Influence of surgical treatment of scoliosis in children with spina bifida on ambulation and motoric skills. Acta Paediatr. 1992;81 (2):173-6.

64. Geiger F, Parsch D, Carstens C. Complications of scoliosis surgery in children with myelomeningocele. Eur Spine J. 1999;8(1):22-6.

65. Sherk HH, Ames MD. Functional results of iliopsoas transfer in myelomeningocele hip dislocations. Clin Orthop Relat Res. 1978;137:181-6.

66. Dias LS, Jasty MJ, Collins P. Rotational deformities of the lower limb in myelomeningocele. Evaluation and treatment. J Bone Joint Surg Am. 1984; 66(2):215-23.

67. Dunteman RC, Vankoski SJ, Dias LS. Internal derotation osteotomy of the tibia: pre- and postoperative gait analysis in persons with high sacral myelomeningocele. J Pediatr Orthop. 2000;20(5):623-8.

68. de Carvalho NJ, Dias LS, Gabrieli AP. Congenital talipes equinovarus in spina bifida: treatment and results. J Pediatr Orthop. 1996;16(6):782-5.

69. Rodrigues RC, Dias LS. Calcaneus deformity in spina bifida: results of anterolateral release. J Pediatr Orthop. 1992;12(4):461-4.

70. Lunsford CD, Abel MF, King KM. Orthoses for Myelomeningocele. Atlas of Orthoses and Assistive Devices: Elsevier; 2019. p. 350-8. e1.

71. Cavalheiro S, da Costa MDS, Moron AF, Leonard J. Comparison of Prenatal and Postnatal Management of Patients with Myelomeningocele. Neurosurg Clin North Am. 2017;28(3):439-48.

72. Adzick NS, Thom EA, Spong CY, Brock JW, Burrows PK, Johnson MP, et al. A Randomized Trial of Prenatal versus Postnatal Repair of Myelomeningocele. New England J Med. 2011;364(11):993-1004.

73. Greene S, Lee PS, Deibert CP, Tempel ZJ, Zwagerman NT, Florio K, et al. The impact of mode of delivery on infant neurologic outcomes in myelomeningocele. Am J Obstetrics Gynecol. 2016;215(4):495.e1-11. 
74. Clayton DB, Tanaka ST, Trusler L, Thomas JC, Pope JC, Adams MC, et al. Long-term urological impact of fetal myelomeningocele closure. J Urol. 2011;186(4 Suppl):1581-5.

75. Asher M, Olson J. Factors affecting the ambulatory status of patients with spina bifida cystica. J Bone Joint Surg Am. 1983;65(3):350-6.

76. Chang C-K, Wong T-T, Huang B-S, Chan R-C, Yang T-F. Spinal dysraphism: a cross-sectional and retrospective multidisciplinary clinic-based study. J Chin Med Assoc 2008;71(10):502-8.

77. Hoffer MM, Feiwell E, Perry R, Perry J, Bonnett C. Functional ambulation in patients with myelomeningocele. J Bone Joint Surg Am 1973;55(1):137-48.

78. Karol LA, King EJOtip, surgery $r$. The orthopaedic management of myelomeningocele. 2000;7(2):53-9.

79. Lullo B, Mueske N, Diamant C, Van Speybroeck A, Ryan D, Wren T, et al. Predictors of walking activity in children and adolescents with myelomeningocele. Arch Phys Med Rehabil. 2020;101(3):450-6.

80. Samdani AF, Fine AL, Sagoo SS, Shah SC, Cahill PJ, Clements DH, et al. A patient with myelomeningocele: is untethering necessary prior to scoliosis correction? Neurosurgical Focus. 2010;29(1):E8.

81. Segal ES, Deatrick JA, Hagelgans NA. The determinants of successful selfcatheterization programs in children with myelomeningoceles. J Pediatric Nursing. 1995;10(2):82-8.

82. Bier JAB, Prince A, Tremont M, Michael Msall. Medical, functional, and social determinants of health-related quality of life in individuals with myelomeningocele. Dev Med Child Neurol. 2005;47(9):609-12.

83. Lindström B, Eriksson BJS-uP. Quality of life for children with disabilities. 1993;38(2):83-9.

84. Müller-Godeffroy E, Michael T, Poster M, Seidel U, Schwarke D, Thyen U, et al. Self-reported health-related quality of life in children and adolescents with myelomeningocele. Dev Med Child Neurol. 2008;50(6):456-61.

85. Tilford JM, Grosse SD, Robbins JM, Pyne JM, Cleves MA, Hobbs CA. Health state preference scores of children with spina bifida and their caregivers. Qual Life Res. 2005;14(4):1087-98.

86. Buffart LM, BERG-EMONS RJVD, MEETEREN JV, Stam HJ, Roebroeck ME. Lifestyle, participation, and health-related quality of life in adolescents and young adults with myelomeningocele. Dev Med Child Neurol. 2009;51(11): 886-94.

87. Snodgrass WT, Adams RC, Keefover-Hicks AJTJoU. Health related quality of life outcomes: Comparison of slings with and without augmentation for continence in myelomeningocele. 2008;179(4S):296.

\section{Publisher's Note}

Springer Nature remains neutral with regard to jurisdictional claims in published maps and institutional affiliations.

Ready to submit your research? Choose BMC and benefit from:

- fast, convenient online submission

- thorough peer review by experienced researchers in your field

- rapid publication on acceptance

- support for research data, including large and complex data types

- gold Open Access which fosters wider collaboration and increased citations

- maximum visibility for your research: over $100 \mathrm{M}$ website views per year

At $\mathrm{BMC}$, research is always in progress.

Learn more biomedcentral.com/submissions 